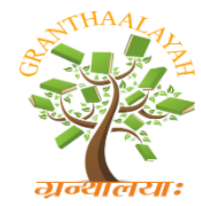

$$
\begin{gathered}
\text { INTERNATIONAL JOURNAL OF RESEARCH - } \\
\text { GRANTHAALAYAH } \\
\text { A knowledge Repository }
\end{gathered}
$$

Science

\title{
DIMINUTION OF REAL POWER LOSS BY VALUE-ADDED BAT ALGORITHM
}

\author{
Dr.K.Lenin *1 \\ ${ }^{* 1}$ Researcher, Jawaharlal Nehru Technological University Kukatpally, Hyderabad 500 085, India
}

DOI: https://doi.org/10.29121/granthaalayah.v5.i6.2017.2047

\begin{abstract}
In this paper, a new Value-added Bat Algorithm (VBA) is proposed to solve reactive power problem. Echolocation is a significant feature of bat behavior and it produce a sound pulse and listens to the echo bouncing back from obstacles whilst flying. Projected VBA algorithm utilizes chaotic behaviour to produce a candidate solution in behaviours analogous to acoustic monophony. Proposed VBA has been tested in Standard IEEE 118 bus system \& practical 191 Indian utility system and simulation results show clearly the better performance of the proposed algorithm in decreasing the real power loss.
\end{abstract}

Keywords: Value-Added Bat Algorithm; Chaotic Behaviour; Optimal Reactive Power; Transmission Loss.

Cite This Article: Dr.K.Lenin. (2017). "DIMINUTION OF REAL POWER LOSS BY VALUEADDED BAT ALGORITHM." International Journal of Research - Granthaalayah, 5(6), 378-388. https://doi.org/10.29121/granthaalayah.v5.i6.2017.2047.

\section{Introduction}

Reactive power optimization places a significant role in optimal operation of power systems. Various numerical methods like the gradient method [1-2], Newton method [3] and linear programming [4-7] have been adopted to solve the optimal reactive power dispatch problem. Both the gradient and Newton methods have the complexity in managing inequality constraints. If linear programming is applied then the input- output function has to be uttered as a set of linear functions which mostly lead to loss of accuracy. The problem of voltage stability and collapse play a major role in power system planning and operation [8]. Evolutionary algorithms such as genetic algorithm have been already proposed to solve the reactive power flow problem [9-11]. Evolutionary algorithm is a heuristic approach used for minimization problems by utilizing nonlinear and non-differentiable continuous space functions. In [12], Hybrid differential evolution algorithm is proposed to improve the voltage stability index. In [13] Biogeography Based algorithm is projected to solve the reactive power dispatch problem. In [14], a fuzzy based method is used to solve the optimal reactive power scheduling method. In 
[15], an improved evolutionary programming is used to solve the optimal reactive power dispatch problem. In [16], the optimal reactive power flow problem is solved by integrating a genetic algorithm with a nonlinear interior point method. In [17], a pattern algorithm is used to solve ac-dc optimal reactive power flow model with the generator capability limits. In [18], F. Capitanescu proposes a two-step approach to evaluate Reactive power reserves with respect to operating constraints and voltage stability. In [19], a programming based approach is used to solve the optimal reactive power dispatch problem. In [20], A. Kargarian et al present a probabilistic algorithm for optimal reactive power provision in hybrid electricity markets with uncertain loads. This paper proposes a new Value-added Bat Algorithm (VBA) to solve reactive power problem. Echolocation is a significant feature of bat behavior and it produce a sound pulse and listens to the echo bouncing back from obstacles whilst flying. This happening has been inspired Yang [21] to build up the Bat Algorithm (BA). Proposed Value-added Bat Algorithm (VBA) utilizes chaotic behaviour to produce a candidate solution in behaviours analogous to acoustic monophony and it has been evaluated in standard IEEE 118 bus test system \& practical 191 Indian utility system. The simulation results show that our proposed approach outperforms all the entitled reported algorithms in minimization of real power loss.

\section{Problem Formulation}

The OPF problem is considered as a general minimization problem with constraints, and can be written in the following form:

Minimize $f(x, u)$

Subject to $g(x, u)=0$

and

$\mathrm{h}(\mathrm{x}, \mathrm{u}) \leq 0$

Where $f(x, u)$ is the objective function. $g(x . u)$ and $h(x, u)$ are respectively the set of equality and inequality constraints. $\mathrm{x}$ is the vector of state variables, and $\mathrm{u}$ is the vector of control variables.

The state variables are the load buses (PQ buses) voltages, angles, the generator reactive powers and the slack active generator power:

$\mathrm{x}=\left(\mathrm{P}_{\mathrm{g} 1}, \theta_{2}, \ldots, \theta_{\mathrm{N}}, \mathrm{V}_{\mathrm{L} 1}, ., \mathrm{V}_{\mathrm{LNL}}, \mathrm{Q}_{\mathrm{g} 1}, \ldots, \mathrm{Q}_{\mathrm{gng}}\right)^{\mathrm{T}}$

The control variables are the generator bus voltages, the shunt capacitors/reactors and the transformers tap-settings:

$\mathrm{u}=\left(\mathrm{V}_{\mathrm{g}}, \mathrm{T}, \mathrm{Q}_{\mathrm{c}}\right)^{\mathrm{T}}$

or

$\mathrm{u}=\left(\mathrm{V}_{\mathrm{g} 1}, \ldots, \mathrm{V}_{\mathrm{gng}}, \mathrm{T}_{1}, \ldots, \mathrm{T}_{\mathrm{Nt}}, \mathrm{Q}_{\mathrm{c} 1}, \ldots, \mathrm{Q}_{\mathrm{cNc}}\right)^{\mathrm{T}}$

Where $\mathrm{Ng}, \mathrm{Nt}$ and $\mathrm{Nc}$ are the number of generators, number of tap transformers and the number of shunt compensators respectively. 


\section{Objective Function}

\section{A. Active Power Loss}

The objective of the reactive power dispatch is to minimize the active power loss in the transmission network, which can be described as follows:

$F=P L=\sum_{k \in N b r} g_{k}\left(V_{i}^{2}+V_{j}^{2}-2 V_{i} V_{j} \cos \theta_{i j}\right)$

or

$F=P L=\sum_{i \in N g} P_{g i}-P_{d}=P_{g s l a c k}+\sum_{i \neq s l a c k}^{N g} P_{g i}-P_{d}$

Where $g_{k}$ : is the conductance of branch between nodes $i$ and $j$, Nbr: is the total number of transmission lines in power systems. $\mathrm{P}_{\mathrm{d}}$ : is the total active power demand, $\mathrm{P}_{\mathrm{gi}}$ : is the generator active power of unit $\mathrm{i}$, and $\mathrm{P}_{\text {gsalck }}$ : is the generator active power of slack bus.

\section{B. Voltage Profile Improvement}

For minimizing the voltage deviation in PQ buses, the objective function becomes:

$F=P L+\omega_{v} \times V D$

Where $\omega_{\mathrm{v}}$ : is a weighting factor of voltage deviation.

VD is the voltage deviation given by:

$V D=\sum_{i=1}^{N p q}\left|V_{i}-1\right|$

Equality Constraint

The equality constraint $\mathrm{g}(\mathrm{x}, \mathrm{u})$ of the ORPD problem is represented by the power balance equation, where the total power generation must cover the total power demand and the power losses:

$P_{G}=P_{D}+P_{L}$

This equation is solved by running Newton Raphson load flow method, by calculating the active power of slack bus to determine active power loss.

\section{Inequality Constraints}

The inequality constraints $\mathrm{h}(\mathrm{x}, \mathrm{u})$ reflect the limits on components in the power system as well as the limits created to ensure system security. Upper and lower bounds on the active power of slack bus, and reactive power of generators:

$P_{\text {gslack }}^{\min } \leq P_{\text {gslack }} \leq P_{\text {gslack }}^{\max }$ 
$Q_{g i}^{\min } \leq Q_{g i} \leq Q_{g i}^{\max }, i \in N_{g}$

Upper and lower bounds on the bus voltage magnitudes:

$V_{i}^{\min } \leq V_{i} \leq V_{i}^{\max }, i \in N$

Upper and lower bounds on the transformers tap ratios:

$T_{i}^{\min } \leq T_{i} \leq T_{i}^{\max }, i \in N_{T}$

Upper and lower bounds on the compensators reactive powers:

$Q_{C}^{\min } \leq Q_{c} \leq Q_{C}^{\max }, i \in N_{C}$

Where $\mathrm{N}$ is the total number of buses, $\mathrm{N}_{\mathrm{T}}$ is the total number of Transformers; $\mathrm{N}_{\mathrm{c}}$ is the total number of shunt reactive compensators.

\section{Bat Algorithm}

Bat algorithm has been developed by Xin-She Yang in 2010 [22]. Bats use sonar echoes to detect and avoid obstacles. They use time delay from emission to reflection and utilize it for navigation. They typically emit short loud, sound impulse and the rate of pulse is usually 10 to20 times per second. Bats uses inbound frequencies $(20,500) \mathrm{kHz}$. By execution [24, 25], Pulse rate can be determined fro range (0-1). Pulse rate can be simply determined from range 0 to 1 , where 0 means there is no emission and by 1, bats are emitting maximum [23], By utilizing above behavior new bat algorithm can be formulated. Yang [22] used three generalized rules for bat algorithm:

a) All bats use echolocation to sense distance, and they also guess the difference between food/prey and background barriers in some magical way.

b) Bats fly randomly with velocity $\vartheta_{i}$ at position $x_{i}$ with a fixed frequency $f_{\text {min }}$, varying wavelength $\lambda$ and loudness $A_{0}$ to search for prey. They can automatically adjust the wavelength (or frequency) of their emitted pulses and adjust the rate of pulse emission $r$ $\in[0 ; 1]$, depending on the proximity of their target.

c) Although the loudness can vary in many ways, we assume that the loudness varies from a large (positive) $A_{0}$ to a minimum constant value $A_{\text {min }}$.

Original Bat Algorithm

a. Objective function $f(x), x=\left(x_{1}, \ldots, x_{d}\right)^{T}$

b. Initialize the bat population $x_{i}$ and $v_{i}$ for $i=1 \ldots n$

c. Define pulse frequency $\mathrm{Q}_{\mathrm{i}} \in\left[\mathrm{Q}_{\min }, \mathrm{Q}_{\max }\right]$

d. Initialize pulse rates $r_{i}$ and the loudness $A_{i}$

e. while $(\mathrm{t}<\mathrm{Tmax}) / /$ number of iterations

f. Generate new solutions by adjusting frequency, and

g. updating velocities and locations/solutions

h. if $\left(\operatorname{rand}(0 ; 1)>r_{i}\right)$

i. Select a solution among the best solutions 
j. Generate a local solution around the best solution

$\mathrm{k}$. end if

1. Generate a new solution by flying randomly

$\mathrm{m}$. if $\left(\operatorname{rand}(0 ; 1)<\mathrm{A}_{\mathrm{i}}\right.$ and $\mathrm{f}\left(\mathrm{x}_{\mathrm{i}}\right)<\mathrm{f}(\mathrm{x})$ )

n. Accept the new solutions

o. Increase $r_{i}$ and reduce $A_{i}$

p. end if

q. Rank the bats and find the current best

r. end while

s. Post process results and visualization

The generation of new solution has been performed by moving virtual bats according the following equations:

$\mathrm{Q}_{\mathrm{i}}^{(\mathrm{t})}=\mathrm{Q}_{\min }+\left(\mathrm{Q}_{\max }-\mathrm{Q}_{\min }\right) \cup(0,1)$,

$v_{i}^{(t+1)}=v_{i}^{t}+\left(x_{i}^{t}-\right.$ best $) Q_{i}^{(t)}$,

$x_{i}^{(t+1)}=x_{i}^{(t)}+v_{i}^{(t)}$

Where $\mathrm{U}(0 ; 1)$ is a uniform distribution.

A random walk with direct exploitation is used for local search that modifies the current best solution according to equation:

$\mathrm{x}^{(\mathrm{t})}=$ best $+\epsilon \mathrm{A}_{\mathrm{i}}^{(\mathrm{t})}(2 \mathrm{U}(0,1)-1)$

Where $\epsilon$ is the scaling factor, and $A_{i}^{(t)}$ the loudness. The local search is launched with the proximity depending on the pulse rate ri and the new solutions accepted with some proximity depending on parameter.. In natural bats, where the rate of pulse emission ri increases and the loudness Ai decreases when a bat finds a prey. The above characteristics can be written by the following equations:

$A_{i}^{(t+1)}=\alpha A_{i}^{(t)}, r_{i}^{(t)}=r_{i}^{(0)}[1-\exp (-\gamma \epsilon)]$

Where $\alpha$ and $\gamma$ and are constants.

\section{Chaos Theory}

Generating random sequences with longer periods and noble consistency is very important for easily simulating complex phenomena, sampling, numerical analysis, decision making and especially in heuristic optimization [26]. Its quality determines the reduction of storage and computation time to achieve a desired accuracy [27]. Chaos is a deterministic, random-like process found in a nonlinear, dynamical system, which is non-period, non-converging and nonbounded. Moreover, it depends on its initial condition and parameters [28-30]. Applications of chaos has several disciplines including operations research, physics, engineering, economics, biology, philosophy and computer science [31-33]. Recently chaos has been prolonged to various optimization areas because it can more easily escape from local minima and progress global 
convergence in comparison with other stochastic optimization algorithms [29-34]. Using chaotic sequences in Bat Algorithm can be helpful to improve the reliability of the global optimality, and they also augment the quality of the results. To tune the bat algorithm chaotic disturbance is introduced. Here, variance $\sigma^{2}$ demonstrates the converge degree of all particles.

$\sigma^{2}=\sum_{i=1}^{N}\left[\left(f_{i}-f_{\text {avg }}\right) / f\right]^{2}$

$f=\max \left\{1, \max \left\{\left|f_{i}-f_{\text {avg }}\right|\right\}\right\}$

Where $f_{i}$ is the fittness of the $i$ th particle; favg is the average fitness value; $f$ is the factor of fitness value. The bigger $\sigma^{2}$ is the broader $i$ th particles will spread. Otherwise, they will almost converge. It is often cited as an example of how complex behaviour can arise from a simple dynamic system without any stochastic disturbance [35]. The equation is the following

$y_{i d}(t+1)=\mu y_{i d}(t)\left(1-y_{i d}(t)\right)$

Where $y_{i d}(t) \in(0,1), i=1, \ldots, N, d=1, \ldots, D . \mu$ is usually set to 4 obtain ergodicity of $y_{i d}(t+$ $1)$ within $(0,1)$. When the initial value $y_{i d}(0) \in\{0.25 .0 .5 .0 .75\}$ using equation (24) we can obtain chaotic sequences. In order to increase the population diversity and prevent premature convergence, we add adaptively chaotic disturbance $P_{c}$ at the time of stagnation. Thus, $P_{c}$ is modified as $P_{c}^{\prime}$.

$p_{c d}^{\prime}(t+1)=p_{c d}(t)+R_{i d}\left(2_{y i d}(t)-1\right)$

$R_{i d}=\beta\left|p_{c d}(t)-p_{i d}(t)\right|$

Where $\beta$ is the region scale factor. Because $y_{i d} \in(0,1)$, the second part of Equation (25) is in the range of $\left(-\left|R_{i d}\right|,\left|R_{i d}\right|\right)$ that would restrict the searching area around $p_{c}$. In addition, the searching range can be adaptively adjusted by the distance between $p_{i}$ and $p_{c}$. If $p_{c}$ is surrounded with the previous best positions $p i$, it means that a good region may have been found, and it is reasonable to search elaborately in a small area. On the contrary, if $p_{i}$ is far from $p_{c}$, this probably suggests that a good area has not yet been found. For better solution, searching region should be enlarged [36].

\section{Implementation of Value-added Bat Algorithm (VBA) in the reactive power Problem}

The implementation of the Value-added Bat Algorithm (VBA) for the optimization problem must find the optimum value of generator bus voltages, the transformer tap setting and reactive power generation to minimize the object function while handling the constraints.

By adding the inequality constraints to the objective function, the augmented fitness function to be minimized becomes:

$\mathrm{F}_{\mathrm{T}}=\mathrm{F}+\lambda_{\mathrm{s}}\left(\mathrm{P}_{\text {gslack }}-\mathrm{P}_{\text {gslack }}^{\lim }\right)^{2}+\lambda_{\mathrm{v}} \sum_{\mathrm{i}=1}^{\mathrm{NL}}\left(\mathrm{V}_{\mathrm{i}}-\mathrm{V}_{\mathrm{i}}^{\mathrm{lim}}\right)^{2}+\lambda_{\mathrm{P}} \sum_{\mathrm{i}=1}^{\mathrm{nbr}}\left(\mathrm{S}_{\mathrm{li}}-\mathrm{S}_{\mathrm{li}}^{\max }\right)^{2}$

Where $\lambda_{\mathrm{S}}, \lambda_{\mathrm{V}}$ and $\lambda_{\mathrm{P}}$ are the penalty factors, these penalty factors are large positive constants. NL is a number of load buses (PQ buses) and Nbr: is the total number of transmission lines.

$\mathrm{S}_{\mathrm{li}}, \mathrm{S}_{\mathrm{li}}^{\max }$ are the apparent powers and maximum apparent powers in transmission line number $\mathrm{i}$, respectively (line flow constraints). 
F is the total active power loss given by (7) or (8).

$\mathrm{V}_{\mathrm{i}}^{\mathrm{lim}}$ and $\mathrm{P}_{\text {gslack }}^{\text {lim }}$ are defined as :

$V_{i}^{\text {lim }}=\left\{\begin{array}{l}V_{i}^{\min } \text { if } V_{i}<V_{i}^{\min } \\ V_{i}^{\max } \text { if } V_{i}>V_{i}^{\max }\end{array}\right.$

$\mathrm{P}_{\text {gslack }}^{\text {lim }}=\left\{\begin{array}{l}\mathrm{P}_{\text {gslack }}^{\min } \text { if } \mathrm{P}_{\text {gslack }}<\mathrm{P}_{\text {gslack }}^{\text {min }} \\ \mathrm{P}_{\text {gslcak }}^{\text {max }} \text { if } \mathrm{P}_{\text {gslack }}>\mathrm{P}_{\text {gslack }}^{\text {max }}\end{array}\right.$

The equality constraint and generators reactive power inequality constraints are handling in Newton Raphson load flow calculation method.

Value-added Bat Algorithm (VBA) for solving optimal reactive power problem.

Objective function $\mathrm{f}(\mathrm{x}), \mathrm{x}=\left(\mathrm{x}_{1}, \ldots, \mathrm{x}_{\mathrm{d}}\right)^{\mathrm{T}}$

Initialize the bat population $x_{i}$ and $v_{i}$ for $i=1 \ldots n$

Define pulse frequency $Q_{i} \in\left[Q_{\text {min }}, Q_{\text {max }}\right]$

Initialize pulse rates $r_{i}$ and the loudness $A_{i}$

While $\left(\mathrm{t}<\mathrm{T}_{\max }\right) / /$ number of iterations

Generate new solutions by adjusting frequency, and

Using the equations update the velocities and locations

$\mathrm{Q}_{\mathrm{i}}^{(\mathrm{t})}=\mathrm{Q}_{\min }+\left(\mathrm{Q}_{\max }-\mathrm{Q}_{\min }\right) s_{i}$ where $s_{i}=$ chaotic map

$\mathrm{v}_{\mathrm{i}}^{(\mathrm{t}+1)}=\mathrm{v}_{\mathrm{i}}^{\mathrm{t}}+\left(\mathrm{x}_{\mathrm{i}}^{\mathrm{t}}-\right.$ best $) \mathrm{Q}_{\mathrm{i}}^{(\mathrm{t})} * s_{i}$

$\mathrm{x}_{\mathrm{i}}^{(\mathrm{t}+1)}=\mathrm{x}_{\mathrm{i}}^{(\mathrm{t})}+\mathrm{v}_{\mathrm{i}}^{(\mathrm{t})}$

if $\left(\right.$ rand $\left.(0 ; 1)>r_{i}\right)$

Select a solution among the best solutions

Generate a local solution around the best solution

end if

Generate a new solution by flying arbitrarily

if $\left(\right.$ rand $(0 ; 1)<\mathrm{A}_{\mathrm{i}}$ and $\mathrm{f}\left(\mathrm{x}_{\mathrm{i}}\right)<\mathrm{f}(\mathrm{x})$ )

Accept the new solutions

Increase $r_{i}$ and reduce $A_{i}$

end if

Rank the bats and find the current best

end while

Post process results and visualization

\section{Simulation Results}

At first Value-added Bat Algorithm (VBA) has been tested in standard IEEE 118-bus test system [37]. The system has 54 generator buses, 64 load buses, 186 branches and 9 of them are with the tap setting transformers. The limits of voltage on generator buses are $0.95-1.1$ per-unit., and on load buses are 0.95 -1.05 per-unit. The limit of transformer rate is $0.9-1.1$, with the changes step of 0.025 . The limitations of reactive power source are listed in Table 1, with the change in step of 0.01 . 
Table 1: Limitation of reactive power sources

\begin{tabular}{|l|l|l|l|l|l|l|l|}
\hline BUS & 5 & 34 & 37 & 44 & 45 & 46 & 48 \\
\hline QCMAX & 0 & 14 & 0 & 10 & 10 & 10 & 15 \\
\hline QCMIN & -40 & 0 & -25 & 0 & 0 & 0 & 0 \\
\hline BUS & 74 & 79 & 82 & 83 & 105 & 107 & 110 \\
\hline QCMAX & 12 & 20 & 20 & 10 & 20 & 6 & 6 \\
\hline QCMIN & 0 & 0 & 0 & 0 & 0 & 0 & 0 \\
\hline
\end{tabular}

The statistical comparison results of 50 trial runs have been list in Table 2 and the results clearly show the better performance of proposed VBA algorithm.

Table 2: Comparison results

\begin{tabular}{|l|l|l|l|l|}
\hline Active power loss (p.u) & $\begin{array}{l}\text { BBO } \\
{[\mathbf{3 8}]}\end{array}$ & $\begin{array}{l}\text { ILSBBO/strategy1 } \\
{[\mathbf{3 8}]}\end{array}$ & $\begin{array}{l}\text { ILSBBO/strategy1 } \\
{[\mathbf{3 8}]}\end{array}$ & $\begin{array}{l}\text { Proposed } \\
\text { VBA }\end{array}$ \\
\hline Min & 128.77 & 126.98 & 124.78 & 116.98 \\
\hline Max & 132.64 & 137.34 & 132.39 & 119.89 \\
\hline Average & 130.21 & 130.37 & 129.22 & 118.05 \\
\hline
\end{tabular}

Then the Value-added Bat Algorithm (VBA) has been tested in practical 191 test system and the following results have been obtained. In Practical 191 test bus system - Number of Generators $=$ 20 , Number of lines $=200$, Number of buses $=191$ Number of transmission lines $=55$. Table 3 shows the optimal control values of practical 191 test system obtained by VBA method. And table 4 shows the results about the value of the real power loss by obtained by Value-added Bat Algorithm (VBA).

Table 3: Optimal Control values of Practical 191 utility (Indian) system by VBA method

\begin{tabular}{|c|c|c|c|}
\hline VG1 & 1.10 & VG 11 & 0.90 \\
\hline VG 2 & 0.79 & VG 12 & 1.00 \\
\hline VG 3 & 1.01 & VG 13 & 1.00 \\
\hline VG 4 & 1.01 & VG 14 & 0.90 \\
\hline VG 5 & 1.10 & VG 15 & 1.00 \\
\hline VG 6 & 1.11 & VG 16 & 1.01 \\
\hline VG 7 & 1.10 & VG 17 & 0.90 \\
\hline VG 8 & 1.01 & VG 18 & 1.00 \\
\hline VG 9 & 1.10 & VG 19 & 1.10 \\
\hline VG 10 & 1.01 & VG 20 & 1.10 \\
\hline
\end{tabular}

\begin{tabular}{|c|c|c|c|c|c|}
\hline $\mathrm{T} 1$ & 1.00 & $\mathrm{~T} 21$ & 0.90 & $\mathrm{~T} 41$ & 0.90 \\
\hline $\mathrm{T} 2$ & 1.01 & T22 & 0.90 & $\mathrm{~T} 42$ & 0.90 \\
\hline T3 & 1.00 & T23 & 0.90 & $\mathrm{~T} 43$ & 0.91 \\
\hline $\mathrm{T} 4$ & 1.10 & T24 & 0.90 & T44 & 0.91 \\
\hline T5 & 1.00 & T25 & 0.90 & $\mathrm{~T} 45$ & 0.91 \\
\hline
\end{tabular}




\begin{tabular}{|c|c|c|c|c|c|}
\hline $\mathrm{T} 6$ & 1.00 & T26 & 1.00 & $\mathrm{~T} 46$ & 0.90 \\
\hline $\mathrm{T} 7$ & 1.00 & T27 & 0.90 & T47 & 0.91 \\
\hline T8 & 1.01 & T28 & 0.90 & $\mathrm{~T} 48$ & 1.00 \\
\hline T9 & 1.00 & T29 & 1.01 & T49 & 0.90 \\
\hline $\mathrm{T} 10$ & 1.00 & T30 & 0.90 & T50 & 0.90 \\
\hline T11 & 0.90 & T31 & 0.90 & T51 & 0.90 \\
\hline $\mathrm{T} 12$ & 1.00 & T32 & 0.90 & T52 & 0.90 \\
\hline T13 & 1.01 & T33 & 1.01 & T53 & 1.00 \\
\hline T14 & 1.01 & T34 & 0.90 & T54 & 0.90 \\
\hline T15 & 1.01 & T35 & 0.90 & T55 & 0.90 \\
\hline T19 & 1.02 & T39 & 0.91 & & \\
\hline T20 & 1.01 & T40 & 0.90 & & \\
\hline
\end{tabular}

Table 4: Optimum real power loss values obtained for practical 191 utility (Indian) system by VBA method.

\begin{tabular}{ll|l}
\hline $\begin{array}{l}\text { Real power Loss } \\
\text { (MW) }\end{array}$ & VBA \\
\hline Min & 145.892 \\
\hline Max & 148.862 \\
\hline Average & 146.992 \\
\hline
\end{tabular}

\section{Conclusion}

In this paper, the Value-added Bat Algorithm (VBA) has been successfully solved the reactive power problem. Proposed VBA algorithm has been tested in Standard IEEE 118 bus system \& practical 191 Indian utility system. The results are compared with the other heuristic methods and the proposed Value-added Bat Algorithm (VBA) algorithm demonstrated its effectiveness and robustness in minimization of real power loss.

\section{References}

[1] O.Alsac,and B. Scott, "Optimal load flow with steady state security",IEEE Transaction. PAS 1973, pp. 745-751.

[2] Lee K Y ,Paru Y M , Oritz J L -A united approach to optimal real and reactive power dispatch , IEEE Transactions on power Apparatus and systems 1985: PAS-104 : 1147-1153

[3] A.Monticelli, M .V.F Pereira ,and S. Granville, "Security constrained optimal power flow with post contingency corrective rescheduling", IEEE Transactions on Power Systems :PWRS-2, No. 1, pp.175-182.,1987.

[4] Deeb N ,Shahidehpur S.M ,Linear reactive power optimization in a large power network using the decomposition approach. IEEE Transactions on power system 1990: 5(2) : 428-435

[5] Hobson ,'Network consrained reactive power control using linear programming, ' IEEE Transactions on power systems PAS -99 (4),pp 868=877, 1980

[6] K.Y Lee ,Y.M Park, and J.L Oritz, "Fuel -cost optimization for both real and reactive power dispatches", IEE Proc; 131C,(3), pp.85-93.

[7] M.K. Mangoli, and K.Y. Lee, "Optimal real and reactive power control using linear programming", Electr.Power Syst.Res, Vol.26, pp.1-10,1993. 
[8] C.A. Canizares , A.C.Z.de Souza and V.H. Quintana , " Comparison of performance indices for detection of proximity to voltage collapse ,' vol. 11. no.3 , pp.1441-1450, Aug 1996.

[9] K.Anburaja, "Optimal power flow using refined genetic algorithm", Electr.Power Compon.Syst , Vol. 30, 1055-1063,2002.

[10] Devaraj, and B. Yeganarayana, "Genetic algorithm based optimal power flow for security enhancement", IEE proc-Generation. Transmission and. Distribution; 152, 6 November 2005.

[11] A. Berizzi, C. Bovo, M. Merlo, and M. Delfanti, "A ga approach to compare orpf objective functions including secondary voltage regulation," Electric Power Systems Research, vol. 84, no. 1, pp. $187-194,2012$.

[12] C.-F. Yang, G. G. Lai, C.-H. Lee, C.-T. Su, and G. W. Chang, "Optimal setting of reactive compensation devices with an improved voltage stability index for voltage stability enhancement," International Journal of Electrical Power and Energy Systems, vol. 37, no. 1, pp. $50-57,2012$.

[13] P. Roy, S. Ghoshal, and S. Thakur, "Optimal var control for improvements in voltage profiles and for real power loss minimization using biogeography based optimization," International Journal of Electrical Power and Energy Systems, vol. 43, no. 1, pp. 830 - 838, 2012.

[14] B. Venkatesh, G. Sadasivam, and M. Khan, "A new optimal reactive power scheduling method for loss minimization and voltage stability margin maximization using successive multi-objective fuzzy lp technique," IEEE Transactions on Power Systems, vol. 15, no. 2, pp. 844 - 851, may 2000.

[15] W. Yan, S. Lu, and D. Yu, "A novel optimal reactive power dispatch method based on an improved hybrid evolutionary programming technique," IEEE Transactions on Power Systems, vol. 19 , no. 2 , pp. $913-918$, may 2004.

[16] W. Yan, F. Liu, C. Chung, and K. Wong, "A hybrid genetic algorithminterior point method for optimal reactive power flow," IEEE Transactions on Power Systems, vol. 21, no. 3, pp. 1163 1169, aug. 2006.

[17] J. Yu, W. Yan, W. Li, C. Chung, and K. Wong, "An unfixed piecewiseoptimal reactive powerflow model and its algorithm for ac-dc systems," IEEE Transactions on Power Systems, vol. 23, no. 1 , pp. $170-176$, feb. 2008.

[18] Capitanescu, "Assessing reactive power reserves with respect to operating constraints and voltage stability," IEEE Transactions on Power Systems, vol. 26, no. 4, pp. 2224-2234, nov. 2011.

[19] Z. Hu, X. Wang, and G. Taylor, "Stochastic optimal reactive power dispatch: Formulation and solution method," International Journal of Electrical Power and Energy Systems, vol. 32, no. 6, pp. $615-621,2010$.

[20] A. Kargarian, M. Raoofat, and M. Mohammadi, "Probabilistic reactive power procurement in hybrid electricity markets with uncertain loads," Electric Power Systems Research, vol. 82, no. 1, pp. $68-80,2012$.

[21] X.S. Yang. Bat algorithm for multi-objective optimisation. International Journal of Bio-Inspired Computation, 3(5):267-274, 2011.

[22] X.S. Yang. A new metaheuristic bat-inspired algorithm. Nature Inspired Cooperative Strategies for Optimization (NICSO 2010), pages 65-74, 2010.

[23] A.H. Gandomi, X.S. Yang, A.H. Alavi, and S. Talatahari. Bat algorithm for constrained optimization tasks. Neural Computing \& Applications, pages 1-17, 2012.

[24] P.W. Tsai, J.S. Pan, B.Y. Liao, M.J. Tsai, and V. Istanda. Bat algorithm inspired algorithm for solving numerical optimization problems. Applied Mechanics and Materials, 148:134-137,2012.

[25] X.S. Yang. Review of meta-heuristics and generalised evolutionary walk algorithm. International Journal of Bio-Inspired Computation, 3(2):77-84, 2011.

[26] L. M. Pecora and T. L. Carroll, "Synchronization in chaotic systems," Physical review letters, vol. 64, pp. 821-824, 1990.

[27] D. Yang, G. Li, and G. Cheng, "On the efficiency of chaos optimization algorithms for global optimization," Chaos, Solitons \& Fractals, vol. 34, pp. 1366-1375, 2007. 
[28] A. H. Gandomi, G. J. Yun, X.-S. Yang, and S. Talatahari, "Chaos-enhanced accelerated particle swarm optimization," Communications in Nonlinear Science and Numerical Simulation, 2012.

[29] O. Abdel-Raouf, I. El-henawy and M. Abdel-Baset "chaotic Harmony Search Algorithm with Different Chaotic Maps for Solving Assignment Problems "International Journal of Computational Engineering \& Management, Vol. 17, pp. 10-15,2014.

[30] W. Gong and S. Wang, "Chaos Ant Colony Optimization and Application," in Internet Computing for Science and Engineering (ICICSE), 2009 Fourth International Conference on, 2009, pp. 301-303.

[31] B. Alatas, "Chaotic bee colony algorithms for global numerical optimization," Expert Systems with Applications, vol. 37, pp. 5682-5687, 2010.

[32] A. Gandomi, X.-S. Yang, S. Talatahari, and A. Alavi, "Firefly algorithm with chaos," Communications in Nonlinear Science and Numerical Simulation, vol. 18, pp. 89-98, 2013.

[33] J. Mingjun and T. Huanwen, "Application of chaos in simulated annealing," Chaos, Solitons \& Fractals, vol. 21, pp. 933-941, 2004.

[34] L. d. S. Coelho and V. C. Mariani, "Use of chaotic sequences in a biologically inspired algorithm for engineering design optimization," Expert Systems with Applications, vol. 34, pp. 1905-1913, 2008.

[35] He, Y.-Y., et al., Comparison of different chaotic maps in particle swarm optimization algorithm for long-term cascaded hydroelectric system scheduling," Chaos, Solitons and Fractals, Vol. 42, 3169-3176, 2009.

[36] Lin, C. and Q.-Y. Feng, Chaotic particle swarm optimization algorithm based on the essence of particle swarm," Journal of Southwest Jiaotong University, Vol. 42, 665-669, 2007.

[37] IEEE, "The IEEE 30-bus test system and the IEEE 118-test system", (1993), http://www.ee.washington.edu/trsearch/pstca/.

[38] Jiangtao Cao, Fuli Wang and Ping Li, "An Improved Biogeography-based Optimization Algorithm for Optimal Reactive Power Flow”, International Journal of Control and Automation Vol.7, No.3 (2014), pp.161-176.

*Corresponding author.

E-mail address: gklenin@gmail.com 